\title{
Düşük Serum D Vitamin Düzeylerine Parathormon Yanıtını Etkileyen Faktörler
}

\author{
Tuğba Aydın ${ }^{\circ}$
}

Sağlık Bilimleri Üniversitesi, İstanbul Fizik Tedavi ve Rehabilitasyon SUAM, Fizik Tedavi ve Rehabilitasyon, İstanbul, Türkiye

Tuğba Aydın, Uzm. Dr.

Illetişim:

Uzm. Dr. Tuğba Aydın

Sağllk Bilimleri Üniversitesi, İstanbul Fizik

Tedavi ve Rehabilitasyon SUAM, Fizik Tedavi ve Rehabilitasyon, İstanbul, Türkiye

Tel: +905324622162

E-Posta:drtugbaaydin@gmail.com

Gönderilme Tarihi : 20 Temmuz 2019

Revizyon Tarihi : 30 Ağustos 2019

Kabul Tarihi $\quad$ : 23 Eylül 2019
ÖZET

Amaç: Serum 25(OH)D vitamini düşüklüğ̈i olan hastalarda parathormon (PTH) yanıtı üzerine etkili faktörleri ortaya koymaktır.

Gereç ve yöntem: Bu çalışma retrospektif tanımlayııı bir çalışmadır. 2015 0cak-2019 Haziran aylarında İstanbul Fizik Tedavi Rehabilitasyon Eğitim ve Araştırma Hastanesi polikliniklerine başvuran, veri tabanından eş zamanlı bakılan kan biyokimyasında serum $25(\mathrm{OH}) \mathrm{D}$ vitamini ve PTH değerleri çalışılmış olan hastalar tarandı. $25(\mathrm{OH}) \mathrm{D}$ vitamini değeri $<30 \mathrm{ng} / \mathrm{mL}$ olan hastalar çalışmaya dahil edildi. 17 yaş ve altında olanlar; kreatinin, albümin, kalsiyum ve fosfor seviyesi normal sınırların dışında olanlar ve PTH seviyesi $<12 \mathrm{pg} / \mathrm{mL}$ olan hastalar çalışmaya dahil edilmedi. Yaş, cinsiyet, hastaneye başvurulan mevsim, serum 25(OH)D vitamini ve PTH seviyeleri kaydedildi. Analizler PASW ver 18 programı ile yapıldı.

Bulgular: Çalışmaya dahil edilen 334 olgunun yaş ortalaması $49,1 \pm 17,7$ yıldı. Serum $25(\mathrm{OH}) \mathrm{D}$ vitamini düzeyi ortalaması $14,5 \pm 7,6 \mathrm{ng} / \mathrm{mL}$, PTH düzeyi ortalaması 49,3 $\pm 26,5 \mathrm{pg} / \mathrm{mL}$ idi. 25 (ОH)D vitamini açısından olguların \%34,43'ünde ciddi eksiklik, $\% 37,43^{\prime}$ ünde eksiklik ve $\% 28,14^{\prime}$ 'ünde yetersizlik saptandı. Tüm olguların $\% 6,3^{\prime}$ ünde hiperparatroidi olduğu saptandı. Ciddi 25(OH)D vitamini eksikliği olan olgularda hiperparatroidi anlamlı olarak daha sık olarak bulundu. Serum PTH düzeyi ve 25(OH)D vitamini düzeyi arasında negatif korelasyon saptandı. Yaş ile serum PTH düzeyi arasında pozitif korelasyon tespit edildi. 25(OH)D vitamini düşüklüğü ile cinsiyet ve mevsimsel dağııım arasında bir ilişki olmadığı saptandı.

Sonuç: 25(OH)D vitamini düşüklüğünün indüklediği PTH yükselmesinde sadece $25(\mathrm{OH}) \mathrm{D}$ vitamini seviyesi değil aynı zamanda yaşın da etkisi vardır. 25(OH)D vitamini düşüklüğü olan kişilerde yaş arttıkça PTH seviyesinin daha yüksek olduğu görüldü.

Anahtar sözcïkler: 25(OH)D vitamini, parathormon, parathormon yanıtı

\section{FACTORS AFFECTING PARATHORMONE RESPONSE TO LOW SERUM VITAMIN D LEVELS}

\section{ABSTRACT}

Objective: The aim of the study is to determine the factors affecting parathormone (PTH) response induced in patients with low serum $25(\mathrm{OH})$ vitamin D levels.

Materials and methods: This is a retrospective descriptive study. The patients whom serum $25(\mathrm{OH})$ vitamin $\mathrm{D}$ and PTH levels were examined together were included in our study in Istanbul in Physical Therapy Rehabilitation Education and Research Hospital between 2015 and 2019. Patients with 25(OH) vitamin D values lower than $30 \mathrm{ng} / \mathrm{mL}$ were included in the study. The patients 17 years and under; the patients with abnormal creatinine, albumin, calcium and phosphorus levels and the patients with PTH levels lower than $12 \mathrm{pg} / \mathrm{mL}$ were excluded from the study. Age, sex, seasonal hospital admission, serum 25(OH) vitamin D and PTH levels were examined.

Results: The mean age of the 334 patients included in the study was $49.1 \pm 17.7$ years. The mean serum $25(\mathrm{OH})$ vitamin $\mathrm{D}$ level was $14.5 \pm 7.6 \mathrm{ng} / \mathrm{mL}$ and the mean PTH level was $49.3 \pm 26.5 \mathrm{pg} / \mathrm{mL}$. $34.4 \%$ of the patients had severe $25(\mathrm{OH})$ vitamin D deficiency, $37.4 \%$ of the patients had $25(\mathrm{OH})$ vitamin $\mathrm{D}$ deficiency and $28.1 \%$ of the patients had $25(\mathrm{OH})$ vitamin $\mathrm{D}$ insufficiency. Hyperparathyroidism was found in $6.3 \%$ of all cases. Hyperparathyroidism was found to be significantly more frequent in patients with severe $25(\mathrm{OH})$ vitamin $\mathrm{D}$ deficiency. There was a negative correlation between serum PTH and $25(\mathrm{OH})$ vitamin D levels. There was a positive correlation between age and serum PTH levels. There was no relationship with $25(\mathrm{OH})$ vitamin D level, gender and seasonal distribution.

Conclusion: Low 25(OH) vitamin D induced PTH elevation is not only dependent on vitamin D levels, but also age. PTH levels were found to be higher in patients with low vitamin $D$ while age increased.

Keywords: $25(\mathrm{OH})$ vitamin D, parathyroid hormone, parathormone response 
D vitamini \%80-90 kadarı UVB ışınları etkisi ile ciltte sentezlenen sekosteroid yapıda bir hormondur. Sentezi için direk güneş ışığına maruziyet gereklidir (1).

D vitamininin bilinen temel fonksiyonu mineral metabolizmasının düzenlenmesidir. Bu etkiyi temel olarak hem kalsiyumun hem de fosfatın bağırsak emilimini arttırması yolu ile yapar. D vitamini PTH salınımını azaltır. Kemik rezorbrsiyonunu ve böbreklerden kalsiyum (Ca) ve magnezyun (Mg) reabsorbsiyonunu arttırır (2).

PTH ve D vitamini birbirini sıkı bir şekilde kontrol eden döngü içindedir. PTH, böbreklerde D vitamini aktifleşmesinin ana uyarıcısı olurken; D vitamini, PTH salgılanması üzerine negatif feedback yapar. Bu döngü üzerindeki majör fizyolojik regülatör dolaşımdaki iyonize Ca'dır. PTH'nın bağırsak, böbrek ve kemik üzerindeki etkileri serum Ca'sını normal aralıkta tutmaya yarar. PTH'nın fosfat (P) metabolizması üzerinde resiprokal etkisi vardır. Buna karşılık, D vitamini hem $\mathrm{Ca}$ hem de $\mathrm{P}$ homeostazında uyarıcı bir etkiye sahiptir ve normal kemik oluşumu için yeterli mineral sağlanmasında kilit rol oynar (2).

25(OH)D düzeyi düştüğünde bağırsaklardan Ca emilimi azalır. Bu durum PTH seviyesini artırır (sekonder hiperparatirodizim). PTH kemiklerden direk Ca mobilizasyonunu artırdığı gibi, böbreklerdeki 1 hidroksilaz enzimzini de aktive eder. Böylelikle 1,25(OH)D vitamini seviyesi yükselir.1,25(OH)D vitamini, kemikten Ca salınımı artırarak, serum Ca seviyesini normale getirir. Ancak bu kompansasyon mekanizması kemik mineralizasyonunu bozmaktadır (3).

Yeterli D vitamini düzeyi, PTH yükselmesine neden olmayacak 25(OH)D vitamini düzeyi olarak tanımlanır. Böylelikle bağırsaklardan emilen Ca yeterli olup, kemikten Ca salınan mekanizmalar devreye girmez. D vitamini seviyesi $\geq 30 \mathrm{ng} / \mathrm{mL}$ ise, PTH'nın azami baskılanmasına dayanarak yaygın olarak"normal" olarak kabul edilir (4).

Klinisyenler, kemik mineral metabolizması bozukluğu (osteoporoz, primer hiperparatiroidi vb.) düşündükleri hastalarda serum PTH ve $25(\mathrm{OH})$ D vitamini seviyelerini rutin olarak ölçmektedir, Ancak sonuçların yorumlanması, bu iki hormon arasındaki ilişsinin ve PTH cevabını değiştiren faktörlerin potansiyel etkisinin açık bir şekilde anlaşılmasını gerektirir (5).

D vitamini düşüklüğüne bağlı olan PTH yükselmesini etkileyen faktörler ile yapılan çalışma sayısı oldukça azdır. Bu çalışmanın amacı serum D vitamini düşüklüğü olan hastalarda PTH yanıtı üzerine etkili faktörleri ortaya koymaktır.

\section{Gereç ve Yöntem}

$\mathrm{Bu}$ çalışma bir retrospektif tanımlayıcı çalışmadır. Çalışma protokolü, Helsinki Deklarasyonu'na uygun olarak 2019/298 onay numarası ile Bakırköy Dr. Sadi Konuk Eğitim ve Araştırma Hastanesi etik kurulu tarafından onaylandı. 2015 Ocak-2019 Haziran aylarında İstanbul Fizik Tedavi Rehabilitasyon Eğitim ve Araştırma Hastanesi polikliniklerine başvuran tüm hastalar tarandı. Hastane veri tabanından eş zamanlı bakılan kan biyokimyasında serum 25(OH)D vitamini ve PTH değerleri çalışılmış olan tüm hastalar seçildi. $25(\mathrm{OH}) \mathrm{D}$ vitamini değeri $<30 \mathrm{ng} / \mathrm{mL}$ olan hastalar çalışmaya dâhil edildi. Yaşı 17'den küçük olan hastalar, kreatinin, albümin, kalsiyum, fosfor seviyesi normal sınırların dışında olan hastalar, PTH seviyesi $<12$ pg/ $\mathrm{mL}$ olanlar çalışma dışı bırakıldı.

Çalışmaya alınma kriterlerine uyan 334 hasta çalışmaya dâhil edildi.

Yaş, cinsiyet, hastaneye başvuru mevsimi, serum 25(OH)D vitamini ve PTH seviyeleri kaydedildi.

Türkiye Endokrin ve Metabolizma Derneğinin önerileri ile; serum $25(\mathrm{OH}) \mathrm{D}$ vitamini düzeyi: $>30 \mathrm{ng} / \mathrm{mL}$ durumlar yeterli; $25(\mathrm{OH})$ D vitamini düzeyi $20-30 \mathrm{ng} / \mathrm{mL}$ ise yetersizlik; $25(\mathrm{OH})$ D vitamini düzeyi $<20 \mathrm{ng} / \mathrm{mL}$ ise eksiklik, 25(OH)D vitamini düzeyi $<10 \mathrm{ng} / \mathrm{mL}$ ise ciddi eksiklik olarak kabul edildi (1). Hastane laboratuvarının serum PTH değeri için normal kabul ettiği 12-88 pg/mL [ng/L] aralığı çalışmamız için de normal aralık olarak kabul edildi.

\section{istatistiksel analiz}

Data tanımlayıcı istatistik (aritmetik ortalama, standart sapma, minimum-maksimum, frekans ve yüzde olarak) sunulmuştur. Dağılımların homojenliği Pearson ki-kare testi analiz edildi. Korelasyon analizleri için Pearson veya Spearman testi ile kullanıldı. Serum PTH seviyesindeki değişim üzerine etkisi olan prediktörleri, karıştırıcı faktörlerin etkisi dikkate alınarak belirlemek üzere çoklu doğrusal regresyon analizi yapıldı. Analizler PASW ver 18 programı ile yapıldı.

\section{Bulgular}

Çalışmaya dahil edilen 334 olgunun yaş ortalaması 49,1 117,7 yıldı. Hastaların $68(\% 20,4)$ sı erkek, $266(\% 79,6)$ si kadın idi. En çok başvurunun sırasıyla kış $(\% 35,0)$, 
ilkbahar $(\% 29,0)$, yaz $(\% 23,3)$ ve sonbahar $(\% 12,6)$ aylarında olduğu gözlendi (Tablo 1).

Serum 25(OH)D vitamini düzeyi ortalaması 14,5 $\pm 7,6 \mathrm{ng} /$ $\mathrm{mL}$, PTH düzeyi ortalaması 49,3 $\pm 26,5 \mathrm{pg} / \mathrm{mL}$ idi (Tablo 1). Bu ölçümlere göre, 25(OH)D vitamini açısından olguların \%34,43'ünde ciddi eksiklik, \%37,43'ünde eksiklik ve \%28,14'ünde yetersizlik saptandı.Tüm olguların \%6,3'ünde hiperparatroidi (n: 21) olduğu saptandı. Hiperparatiroidisi olan hastalarda, $25(\mathrm{OH})$ D vitamini hastaların \%61,9'unda ciddi eksik, \%28,6'sında eksik ve \%9,5'inde yetersiz olarak saptandı. PTH seviyesi normal olan hastalarda $25(\mathrm{OH})$ D vitamini seviyesi hastaların \%32,6'sında ciddi eksik, \%38,0'ında eksik ve \%29,4'ünde yetersiz olarak saptandı. Ciddi 25(OH)D vitamini eksikliği olan olgularda hiperparatroidi anlamlı olarak daha sık olarak bulundu (Pearson ki-kare, $p=0,017$ ) (Şekil 1).

\begin{tabular}{|c|c|c|c|c|}
\hline Toplam & & Min-Maks & \multicolumn{2}{|c|}{ Ort. $\pm s . s . / n-\%$} \\
\hline Yaş & & $17-91$ & \multicolumn{2}{|c|}{$49,1 \pm 17,7$} \\
\hline \multirow{2}{*}{ Cinsiyet } & Kadın & & 266 & $79,6 \%$ \\
\hline & Erkek & & 68 & $20,4 \%$ \\
\hline \multirow{4}{*}{ Mevsim } & İlkbahar & & 97 & $29,0 \%$ \\
\hline & Yaz & & 78 & $23,3 \%$ \\
\hline & Sonbahar & & 42 & $12,6 \%$ \\
\hline & Kış & & 117 & $35,0 \%$ \\
\hline $25(\mathrm{OH}) \mathrm{D}$ vitamini & & $1,00-29,4$ & \multicolumn{2}{|c|}{$14,5 \pm 7,6$} \\
\hline PTH & & $13.8-207,1$ & \multicolumn{2}{|c|}{$49,3 \pm 26,5$} \\
\hline
\end{tabular}

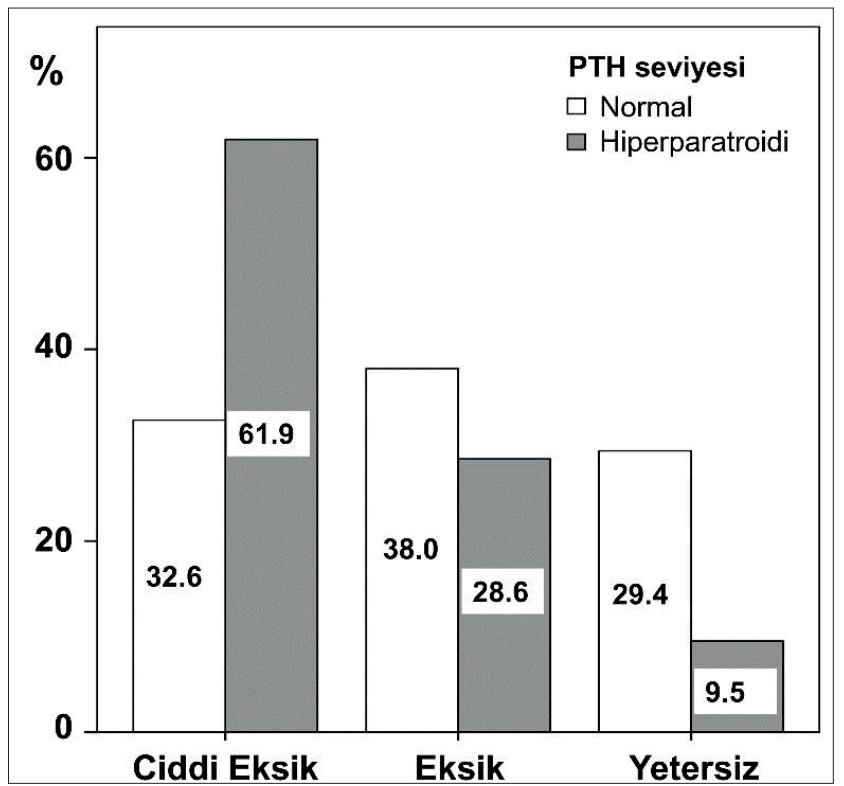

Şekil 1. Serum 25(OH)D vitamini düşüklüğü ve PTH seviyesi.
Serum PTH düzeyi ve 25(OH)D vitamini düzeyi arasında negatif korelasyon saptandı (Pearson korelasyon, $\mathrm{R}=-$ $0,236, p=0,0001$ ) (Şekil 2).

Yaş ile serum PTH düzeyi arasında zayıf pozitif korelasyon saptandı (Pearson korelasyon, $\mathrm{R}=0,181, \mathrm{p}=0,001$ ) (Şekil 3). Yaş ile serum $25 \mathrm{OH}$ vitamin $\mathrm{D}$ düzeyi arasında bir korelasyon olmadığı saptandı (Pearson korelasyon, $R=0,045$, $p=0,334$ )

25(OH)D vitamini düşüklüğü ile cinsiyet arasında bir ilişki olmadığı saptandı (Spearman korelasyon, R=-0,043, $p=0,533)$. 25(OH)D vitamini düşüklüğü ile mevsimsel

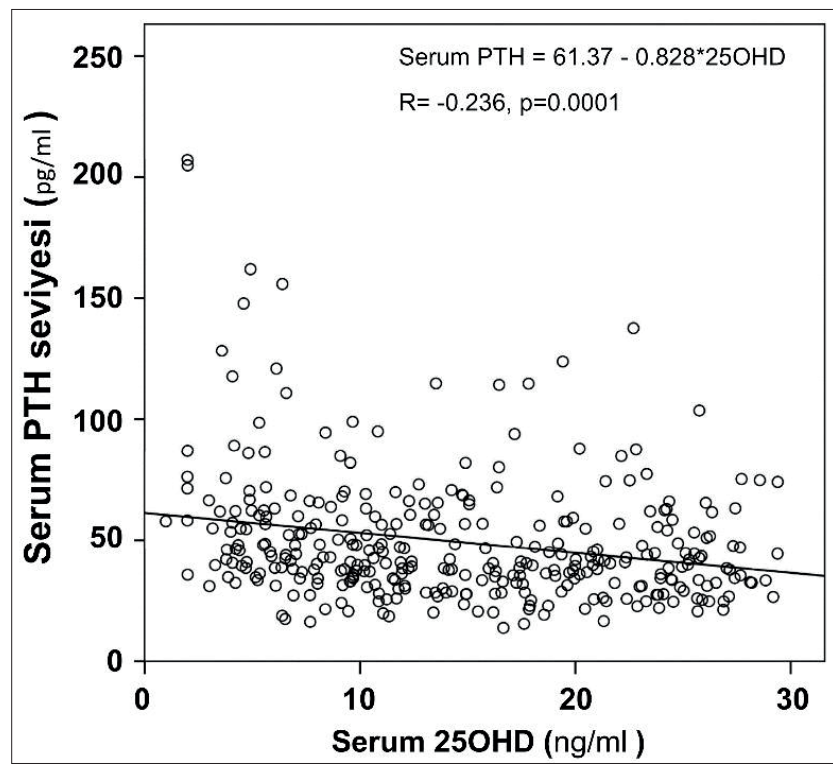

Şekil 2. Serum PTH ve 25(OH)D vitamini düzeyi arasında korelasyon.

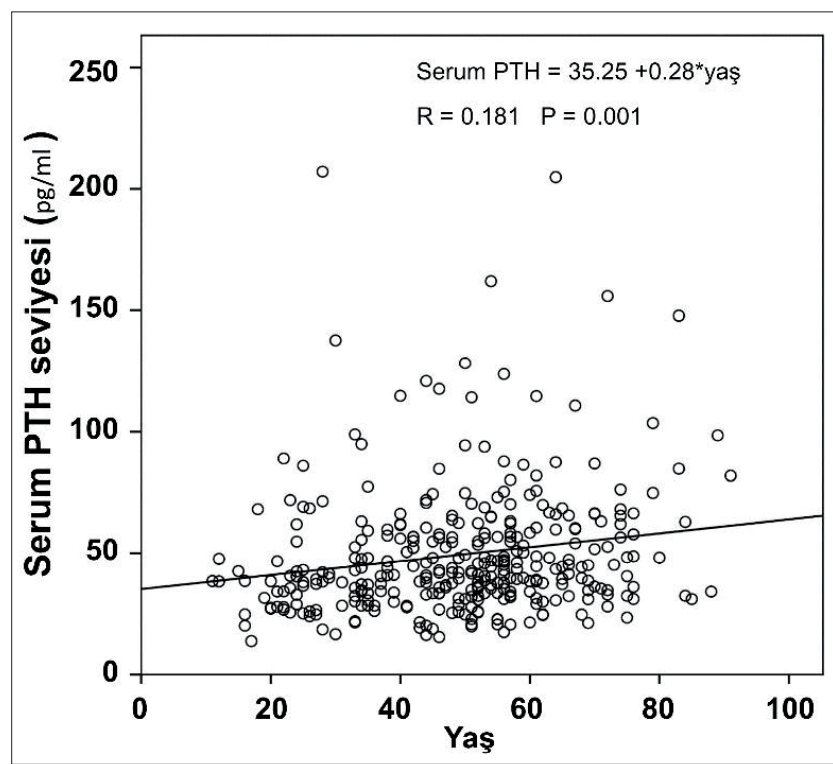

Şekil 3. Serum PTH düzeyi ve yaş arasında korelasyon. 
dağılım arasında bir ilişki olmadığı saptandı (Spearman korelasyon, $\mathrm{R}=-0,048, \mathrm{p}=0,385$ )

Çoklu regresyon analizi, serum 25(OH)D vitamini düşük olan olgularda serum PTH düzeyindeki yükselmeden serum $25(\mathrm{OH}) \mathrm{D}$ vitamini düzeyinin $\% 24,5$, ileri yaşın ise $\% 19,5$ oranında sorumlu olduğunu göstermektedir ( $F=16,8, p=.0,00001$ ) (Tablo 2).

\begin{tabular}{|c|c|c|c|c|c|c|c|}
\hline & \multirow{2}{*}{$\begin{array}{l}\begin{array}{l}\text { Standardize } \\
\text { sabit (Beta) }\end{array} \\
\text { Odds oranı }\end{array}$} & \multirow[b]{2}{*}{$t$} & \multirow[b]{2}{*}{$\begin{array}{c}P \\
\text { değeri }\end{array}$} & \multicolumn{2}{|c|}{$\begin{array}{l}\text { 95\% Güven } \\
\text { aralığı }\end{array}$} & \multirow[t]{2}{*}{ VIF } & \multirow[b]{2}{*}{$\begin{array}{l}\text { Durbin } \\
\text { Watson }\end{array}$} \\
\hline & & & & $\begin{array}{c}\text { Alt } \\
\text { sInır }\end{array}$ & $\begin{array}{l}\text { Üst } \\
\text { sınır }\end{array}$ & & \\
\hline (Sabit) & & 9.4 & 0.0001 & 37.072 & & & 0.883 \\
\hline $\begin{array}{l}25(\mathrm{OH}) \mathrm{D} \\
\text { vitamini }\end{array}$ & -0.245 & -4.6 & 0.0001 & -1.218 & 1.002 & 0.998 & \\
\hline Yaş & 0.192 & 3.6 & 0.0001 & 0.141 & 1.002 & 0.998 & \\
\hline
\end{tabular}

\section{Tartışma}

PTH sentezi ve salgılanması $25(\mathrm{OH}) \mathrm{D}$ vitamini eksikliği olan kişilerde daha yüksektir. Hem PTH hem de 25(OH) D vitamini, kalsiyum homeostazında önemli rol oynar. Serum PTH'nin kronik yükselmeleri osteoklast aktivitesini ve fosforun idrarla atılımını arttırır, böylece kemik yoğunluğu üzerinde olumsuz bir etkisi vardır (6). Ancak $D$ vitamini düşüklüğü olan tüm hastalarda PTH artışı izlenmemektedir (7). Serum 25(OH)D vitamini düzeyleri düşük olarak saptanan hastalarda farklı PTH yanıtının nedenlerini araştıracak yeni çalışmalara intiyaç duyulmaktadır (8). Bu çalışma ülkemizde serum $D$ vitamini düşüklüğü olan hastalarda PTH yanıtı üzerine etkili faktörleri inceleyen hasta sayısı fazla olan ilk çalışmadır.

Özdemir ve ark.'nın serum $D$ vitamini düşüklüğü olan kadın hastalarda yaptıkları çalışmada $25(\mathrm{OH}) \mathrm{D}$ vitamini ortalamasını 8,8 $\pm 3,9 \mathrm{ng} / \mathrm{mL}$ olarak bulmuşlardır. Bizim çalışmamızda ise serum 25(OH)D vitamini ortalaması $14,5 \pm 7,6 \mathrm{ng} / \mathrm{mL}$ olarak tespit edildi. Her iki çalışmada da örneklem gurubunu sadece $25(\mathrm{OH}) \mathrm{D}$ vitamini düşüklüğü olan hastalar oluşturmaktadır. Bizim çalışmamızda $25(\mathrm{OH})$ D vitamini düzeyinde olan yaklaşık $6 \mathrm{ng} / \mathrm{mL}$ fazlalığın, erkeklerin de çalışmaya dâhil edilmiş olmasından kaynaklandığını düşünmekteyiz. Ayrıca Özdemir'in yapmış olduğu çalışmada hastaların \%22,42'ünde $25(\mathrm{OH}) \mathrm{D}$ vitamini yetersizliği, \%77,6 ise $25(\mathrm{OH})$ D vitamini eksikliği mevcuttu, bizim çalışmamız ise bu çalışmaya benzer olarak olguların \%28,14'ünde yetersizlik, \%71,86'sında eksiklik (\%34,43'ünde ciddi eksiklik + \%37,43'ünde eksiklik) saptandı. Özdemir'in çalışmasında hastaların serum PTH seviyesi ortalaması $68,2 \pm 29,7 \mathrm{pg} / \mathrm{mL}$ olarak tespit edilmiştir. Bizim hastalarımızın PTH seviyesi ortalaması ise 49,3 $\pm 26,5$ $\mathrm{pg} / \mathrm{mL}$ idi. Onların çalışmasındaki bu PTH yüksekliğinin, Özdemir'in çalışmasındaki hastaların bizimkinden daha düşük olan 25(OH)D vitamini düzeyine bağlı olarak geliştiğini düşünmekteyiz (8).

Vurgun ve ark. çalışmalarında PTH düzeyinin, 25(OH)D vitamin düzeyine göre sapma noktasını saptayıp, erişkin Türk toplumundaki $D$ vitamini eksiklik sınır değerini bulmayı amaçlamışlardır. Bu amaçla 1684 hasta taramışlardır. $25(\mathrm{OH}) \mathrm{D}$ vitamini $>50 \mathrm{ng} / \mathrm{mL}$ olduğunda PTH'nin baskılandığını, 25(OH)D vitamini $50-10 \mathrm{ng} / \mathrm{mL}$ arasındayken PTH'nın stabil kaldığını, 25(OH)D vitamini değeri $<10 \mathrm{ng} /$ mL olduğu anda PTH'nın ilk artış cevabı verdiğini bulmuşlardır. Bu PTH cevabına göre, Vurgun ve ark. erişkin Türk toplumundaki $25(\mathrm{OH}) \mathrm{D}$ vitamini eksiklik sınır değerinin tüm mevsimlerde $10 \mathrm{ng} / \mathrm{mL}$ olarak kullanılmasını önermektedirler (9). Valcour ve ark.'nın çalışmasında serum $25(\mathrm{OH})$ D vitamini $<20 \mathrm{ng} / \mathrm{mL}$ olan hastaların \%40'ında, serum $25(\mathrm{OH}) \mathrm{D}$ vitamin $<10 \mathrm{ng} / \mathrm{mL}$ olan hastaların ise $\% 51$ 'inde hiperparatiroidi saptanmıştır (5). Bizim olgularımızda ise tüm olguların sadece $\% 6,3$ 'ünde hiperparatroidi olduğu saptandı. Bizim örneklem grubumuzun 25(OH)D vitamin seviyesi $<30 \mathrm{ng} / \mathrm{mL}$ olması ve Türk toplumu için hiperparatiroidi oluşturan 25(OH)D vitamin seviyesinin $<10 \mathrm{ng} / \mathrm{mL}$ olduğu düşünüldüğünde, Valcour ve ark.'nın çalışması ile bizim çalışmamız arasındaki hiperparatiroidi oranı farkını açıklamaktadır. Valcour ve ark.'nın çalışmasında olduğu gibi bizim çalışmamızda da ciddi $25(\mathrm{OH})$ D vitamini eksikliği olan $(25(\mathrm{OH}) \mathrm{D}$ vitamini düzeyi $<10$ $\mathrm{ng} / \mathrm{mL}=$ ciddi eksiklik) olgularda hiperparatroidi anlamI olarak daha sık olarak bulunmuştur (Pearson ki-kare, $\mathrm{p}=0,017)$ ) Çalışmamızda; serum 25(OH)D vitamini düşük olan olgularda, serum PTH düzeyindeki değişimden serum $25(\mathrm{OH})$ D vitamini düzeyinin $\% 24,5$ oranında sorumlu olduğu bulunmuştur.

25(OH)D vitamini eksikliğinde, serum Ca düzeyini artırabilmek amacıyla serum PTH seviyelerinin yükseldiği çok iyi bilinmektedir $(2,10)$. Bizim çalışmamı da bu klasik bilgiyi destekler nitelikte olup serum PTH düzeyi ve $25(\mathrm{OH}) \mathrm{D}$ vitamini düzeyi arasında negatif korelasyon saptanmıştır.

PTH'da sekonder artış; 25(OH)D vitamin eksikliği, bağısaklardan yetersiz Ca emilimi, bozulmuş böbrek fonksiyonu, yetersiz Ca alımı ve östrojen azalması gibi çeşitli faktörlere bağlı olarak yaşlılarda daha sık bulunur (11). Bizim 
çalışmamızda da yaş ile serum PTH düzeyi arasında pozitif korelasyon saptanmıştır. Ek olarak çalışmamızda serum 25(OH)D vitamini düşük olan olgularda serum PTH düzeyindeki değişimden ileri yaşın \%19,5 oranında sorumlu olduğu bulunmuştur. Ayrıca hastalarımızın hepsinin serum Ca değeri normal seviyede bulunmaktadır. Bu durum bize optimal serum Ca değerini sağlamak için yaşlılarda daha fazla PTH salgılanması gerektiğini düşündürmüştür. Çalışmamızda yaş ile serum 25(OH)D vitamini düzeyi arasında bir korelasyon olmadığı saptanmasına rağmen, yaş ile birlikte PTH salınımında artış olduğu bulundu. Valcour ve ark.'nın çalışmasında da belirttiği gibi D vitamini eksikliğinin, yaş ile birlikte PTH düzeyleri üzerine daha fazla artan etkisi bulunması; yaşlanma ile birlikte bağırsaklardan azalan Ca emilimi ve/veya azalan böbrek fonksiyonu ile serum Ca'daki azalmaya bağlı olduğu söylenebilir. Yine Valcour ve ark.'nın çalışmalarının sonucunda söylediği, yaşlılarda uzun süreli $D$ vitamini eksikliğinin daha fazla PTH salgılatarak, paratiroid bezi hiperplazisine neden olabileceği veya paratiroid adenomlarının gelişmesine yol açabileceği hipotezi çalışmamızın bu verileri ile de desteklenmektedir. PTH düzeyi ile $25(\mathrm{OH})$ D vitamini düzeyi arasındaki ilişkinin ilerleyen yaş ile daha güçlü olmasına neden olan fizyolojiyi anlamak için kapsamlı klinik çalışmalar gerekmektedir (5).

\section{Kaynaklar}

1. Türkiye Endokrin ve Metabolizma Derneği. Osteoporoz ve Metabolik Kemik Hastalıkları Tanı ve Tedavi Kılavuzu 9. Baskı. Ankara: Miki Matbaacilık; 2018.

2. Khundmiri SJ, Murray RD, Lederer E. PTH and Vitamin D. Compr Physiol 201615;6:561-601. [CrossRef]

3. Yavuz D, Mete T, Yavuz R, Altunoğlu A. D Vitamini, Kalsiyum \& Mineral Metabolizması, D Vitaminin İskelet Dışı Etkileri ve Kronik Böbrek Yetmezliğinde Nutrisyonel D Vitamini Kullanımı. Ankara Med J 2014;14:162-71. [CrossRef]

4. Wright NC, Chen L, Niu J, Neogi T, Javiad K, Nevitt MA, et al. Defining physiologically "normal" vitamin D in African Americans. Osteoporos Int 2012;23:2283-91. [CrossRef]

5. Valcour A, Blocki F, Hawkins DM, Rao SD. Effects of age and serum 25-OH-vitamin D on serum parathyroid hormone levels. J Clin Endocrinol Metab 2012;97:3989-95. [CrossRef]

6. Lotito A, Teramoto M, Cheung M, Becker K, Sukumar D. Serum Parathyroid Hormone Responses to Vitamin D Supplementation in Overweight/Obese Adults: A Systematic Review and Meta-Analysis of Randomized Clinical Trials. Nutrients 2017:9:241. [CrossRef]

7. Sahota O, Mundey MK, San P, Godber IM, Lawson N, Hosking DJ. The relationship between vitamin $\mathrm{D}$ and parathyroid hormone: calcium homeostasis, bone turnover, and bone mineral density in postmenopausal women with established osteoporosis. Bone 2004;35:312-9. [CrossRef]
Khazaei ve ark'nın 102 sağlıklı kişide yaptıkları çalışmalarında bizim çalışmamıza benzer şekilde, $25(\mathrm{OH}) \mathrm{D}$ vitamini düşüklüğü ile cinsiyet arasında ilişki bulamamışlardır (12).

Bulunduğu konum nedeni ile ülkemizde $D$ vitamini sentezi Mayıs-Kasım ayları arasında gerçekleşir (1). Bozkurt ve ark.'nın çalışmasına göre yetişkin Türk nüfusunun büyük çoğunluğu kış ve yaz aylarında yetersiz 25(OH)D vitamini seviyelerine sahiptir. Ayrıca yine bu çalışmaya göre serum 25(OH)D vitamini düzeyleri kış aylarında yaz mevsimine göre anlamlı derecede düşüktür (kış aylarında ortalama vit D: $13,9 \mathrm{ng} / \mathrm{mL}$, yaz aylarında ortalama 19,7 ng/mL). $25(\mathrm{OH})$ D vitamini eksikliği sıklığı kışın \%94, yazın ise $\% 85$ olarak bulunmuştur (13). Ancak bizim çalışmamızda D vitamini düşüklüğü ile mevsimsel dağılım arasında bir ilişki bulunamamıştır. Hastalara düzenli yapılan D vitamini takviyelerinin kış aylarında daha düşük olması gereken $25(\mathrm{OH})$ D vitamini oranlarını çalışmamızda bozduğunu düşünmekteyiz.

\section{Sonuç}

$25(\mathrm{OH}) \mathrm{D}$ vitamini düşüklüğünün indüklediği PTH yükselmesinde sadece $25(\mathrm{OH}) \mathrm{D}$ vitamini seviyesi değil aynı zamanda yaşın da etkisi vardır. 25(OH)D vitamini düşüklüğü olan kişilerde yaş arttıkça PTH seviyesinin daha yüksek olduğu görüldü.

8. Özdemir O. Serum 25(OH) Vitamin D Düzeyi Düşük Olan Kadınlarda Paratiroid Hormon Yanıtının Değerlendirilmesi. Turk Med J 2008;2:124-7. https://www.journalagent.com/ttd/pdfs/ TTD_2_3_124_127.pdf

9. Vurgun E, Evliyaoğlu O, Vardar M. Assessment of vitamin D deficiency level by the physiological response of parathyroid hormone in Turkish adults. Turk J Biochem 2018;43:502-9. [CrossRef]

10. Chapuy MC, Preziosi P, Maamer M, Arnaud S, Galan P, Hercberg S, Meunier P. Prevalence of vitamin D insufficiency in an adult normal population. Osteoporosis Int 1997;7:439-43. [CrossRef]

11. Di Monaco M, Castiglioni C, Vallero F, Di Monaco R, Tappero R. Parathyroid hormone response to severe vitamin $D$ deficiency is sex associated: an observational study of 571 hip fracture inpatients. J Nutr Health Aging 2013;17:180-4. [CrossRef]

12. Khazaei Z, Khazaei S, Beigrezaei S, Nasri H. Vitamin D deficiency in healthy people and its relationship with gender and age. J Parathyroid Dis 2018;6:16-8. [CrossRef]

13. Bozkurt S, Alkan BM, Yildiz F, Gümüş S, Sezer N, Ardiçoğlu Ö, Akkuş S. Age, Sex, and Seasonal Variations in the Serum Vitamin D3 Levels in a Local Turkish Population. Arch Rheumatol 2014;29:14-19. [CrossRef] 